\title{
O DIREITO TRIBUTÁRIO COMO INSTRUMENTO PARA REDUÇÃO DA DESIGUALDADE SOCIAL: ENTRE AS LIÇÕES DE PIKETTY E O DEVER FUNDAMENTAL DE PAGAR IMPOSTOS
}

\author{
Antônio Carlos Suppes Doorgal de Andrada ${ }^{1}$ \\ Alex da Silva Alvarenga ${ }^{2}$
}

\section{RESUMO}

Este trabalho discorre sobre as constatações concernentes à desigualdade social apresentadas por PIKETTY (2013), na obra O Capital no Século XXI e sua compatibilidade com a realidade brasileira, conforme dados apresentados por MILÁ (2015) e pela Receita Federal (2016). Adiante, analisa-se sua proposta de redução da desigualdade através da progressividade fiscal e a compatibilidade desta com o Direito brasileiro, partindo das premissas da Constituição da República e a jurisprudência recente do Supremo Tribunal Federal, que aplicou, no julgamento conjunto das ADI's 2.390, 2.386, 2.397 e 2.859, realizado em 2016, a teoria sobre o dever fundamental de pagar impostos NABAIS (1998).

Palavras-chave: Desigualdade social; Piketty; Progressividade fiscal; Brasil; Dever fundamental de pagar impostos.

\section{TAXATION AS AN INSTRUMENT TO REDUCE SOCIAL INEQUALITY: BETWEEN PIKETTY LESSONS AND THE FUNDAMENTAL DUTY OF PAYING TAXES}

\begin{abstract}
This paper discusses PIKETTY (2013) findings on social inequality, in his book Le capital au XXIe siècle and it's applicability in Brazilian reality, accordingly to MILÁ (2015) issue and brazilian revenue service database. Moreover, it's presented the proposition of PIKETTY (2013), to reduce inequality with progressive taxes and the compatibility of that proposition to brazilian law, especially to its Constitution and the recent cases decided by brazilian Supreme Court that recognized the theory of the fundamental duty to pay taxes.
\end{abstract}

Keywords: Social inequality; Piketty; Progressive taxes; Brazil; Extrafiscality; Fundamental duty of paying taxes.

\section{INTRODUÇÃO}

Thomas PIKETTY (2013) desenvolveu longo estudo em que mapeou a distribuição da renda e da riqueza em diversos países do mundo, destacando-se, entre outros, os Estados Unidos, Reino Unido, França, Suécia e o Japão. Seu profundo estudo consubstanciou-se na

\footnotetext{
${ }^{1}$ Mestrando em Direito nas Relações Econômicas e Sociais pela Faculdade de Direito Milton Campos - Nova Lima/MG.

${ }^{2}$ Mestrando em Direito nas Relações Econômicas e Sociais pela Faculdade de Direito Milton Campos - Nova Lima/MG.
} 
obra $O$ Capital no Século XXI, em que o autor, após realizar o mapeamento da desigualdade econômica mundial, apresenta algumas propostas para sua redução, especialmente por meio do Direito Tributário, ao propor a utilização da progressividade fiscal e da tributação de grandes fortunas.

Neste sentido, o artigo tem como objetivo apresentar os estudos de PIKETTY (2013) sobre a estrutura da desigualdade social, bem como demonstrar que o Brasil, embora não tenha sido seu foco de análise, se enquadra perfeitamente no mesmo contexto de alta desigualdade social, com grandes concentrações de renda e riqueza, conforme estudos realizados por MILÁ (2015) e dados oficiais apresentados pela Receita Federal do Brasil no Relatório da Distribuição Pessoal da Renda e da Riqueza da População Brasileira (2016), formulado com base nos dados do Imposto de Renda de Pessoas Físicas de 2015/2014.

Estabelecidas as premissas iniciais - de que há um quadro de desigualdade sistêmico e histórico no Brasil -, passa-se a análise da compatibilidade das propostas apresentadas por PIKETTY (2013) com o Direito Brasileiro. Assim, após apresentação das "lições de Piketty" no capítulo dois, no seguinte abordar-se-ão as premissas básicas do sistema tributário nacional estabelecidas na Constituição da República.

Mais adiante, no capítulo quatro, de modo a reforçar a importância do Direito Tributário, apresentar-se-á a teoria desenvolvida por NABAIS (1998), jurista português que sistematizou o dever fundamental de pagar tributos. Apesar de apresentada há quase duas décadas, sua teoria permanece recente e, atualmente, recebeu especial atenção no Supremo Tribunal Federal - STF, que a aplicou expressamente no julgamento conjunto das Ações Diretas de Inconstitucionalidade - ADI's 2.390, 2.386, 2.397 e 2.859, julgadas em fevereiro de 2016 pelo plenário da Suprema Corte.

Quanto à metodologia a ser utilizada no artigo, inicialmente será utilizada a pesquisa bibliográfica, com base nos estudos por PIKETTY (2013) sobre a desigualdade no mundo. Em seguida, com base na pesquisa de dados indireta, obtida através de estudos oficias (da Receita Federal, 2016) e extraoficiais (MILÁ, 2015), serão analisadas as semelhanças dos contextos mundial e nacional (brasileiro). Adiante, a fim de se demonstrar a compatibilidade das propostas de PIKETTY (2013) com o direito brasileiro, serão analisadas obras doutrinárias, especialmente relativas ao Direito Tributário e análise de recente precedente fixado pelo Supremo Tribunal Federal. 
Por fim, serão tecidas as considerações finais, demonstrando a pertinência da proposta de PIKETTY (2013) com o direito brasileiro, sobretudo considerando o dever fundamental de pagar impostos e as bases do sistema tributário nacional, sustentado pelo princípio da capacidade contributiva e da progressividade fiscal.

\section{AS LIÇÕES DE PIKETTY: A CONCENTRAÇÃO DE RIQUEZA E A PROGRESSIVIDADE FISCAL.}

Um dos pontos centrais do trabalho de PIKETTY (2013) está na constatação de que aqueles que detêm altas concentrações de capital tendem a, cada vez mais, concentrar mais capital. Isso porque, historicamente, a renda do capital tem sido superior à renda do trabalho, o que contribuiu para que as classes mais abastadas recebessem mais que as outras, sem que tenham que, necessariamente, produzir.

Desde já, é importante destacar que a concentração mundial de riqueza apresentada por PIKETTY (2013) pode ser observada ao menos sob dois enfoques: de um lado, entre os países e, de outro, internamente, entre as pessoas que os constituem. Em ambos os aspectos o autor demonstra haver grande desigualdade. Veja-se no plano mundial, em que PIKETTY (2013, p. 66) demonstra que desde o ano de 1.700 até 1.990 , a concentração da riqueza mundial na Europa e nos Estados Unidos foi constante. Entretanto, o foco central do presente estudo será a análise da concentração de riqueza entre as pessoas físicas dentro de cada país, para que sejam posteriormente analisadas as possibilidades de redução por meio do Direito Tributário.

A estrutura da concentração de riqueza apresentada por PIKETTY (2013) é complexa, pois o autor demonstra que a desigualdade econômica é sistêmica, existindo não só entre os países, mas, sobretudo, internamente, entre as pessoas físicas. Para demonstrar como isso vem ocorrendo há tempos na história mundial, o autor recorre à literatura. Para tanto, cita trecho do famoso romance $O$ pai Goriot, de Balzac, em que um de seus personagens, com o intuito de convencer um terceiro a cometer um assassinato para que obtenha uma herança, demonstra de forma clara como a renda do capital historicamente se sobrepõe à do trabalho. Transcreve-se trecho do romance citado por PIKETTY (2013, p. 235), em que o personagem Vautrin afirma a seu interlocutor: 
Por volta dos trinta anos, você será juiz, recebendo 1.200 francos por ano, e isso se não tiver desistido da carreira. Quando chegar aos quarenta anos, desposará a filha de um moleiro, com uma renda de uns 6.000 francos. Muito obrigado. Se tiver a sorte de encontrar um patrono, há de tornar-se procurador do rei aos trinta anos, com uma remuneração de 1.000 écus [5.000 francos], e se casará com a filha do prefeito. Se estiver disposto a cometer algumas pequenas baixezas políticas, será, aos quarenta anos, procurador-geral. (...) Tenho a honra de lhe fazer notar ainda que não há mais de vinte procuradores-gerais na França, e que você está entre os vinte mil aspirantes ao cargo, entre os quais há palhaços que venderiam suas famílias para subir apenas um degrau. Se essa carreira lhe desagrada, considere outra situação. $\mathrm{O}$ barão de Rastignac, será que ele quer ser advogado? Ah, que bom! Nesse caso, você terá de padecer durante dez anos, gastar 1.000 francos por mês, adquirir uma biblioteca, um escritório, frequentar a sociedade, beijar as vestes de outro advogado para conseguir casos e clientes, varrer o palácio com sua língua. Se essa carreira o levasse a algum lugar, eu não o desencorajaria; porém, consegue encontrar em Paris cinco advogados que, aos cinquenta anos, ganhem mais do que 50.000 francos por ano? (PIKETTY, 2013, p. 235)

O trecho literário destacado demonstra, de uma forma sucinta, como a renda do trabalho é muito mais árdua que a renda do capital. Enquanto a primeira demanda um grande esforço para se obter pouco, a segunda permite arrecadar altos valores sem qualquer gasto de energia de forma ainda mais eficiente.

Não bastasse a desigualdade da renda do capital frente a renda do trabalho, há uma desigualdade interna na renda do capital que é por demais acentuada. Isso significa, portanto, que dentre aqueles que obtêm sua renda do capital, os que se situam no topo das camadas superiores ganham valores nitidamente maiores, o que acentua ainda mais a desigualdade. De uma forma mais precisa, explica PIKETTY (2013, p. 11):

$\mathrm{Na}$ prática, a primeira regularidade observada quando se busca medir a desigualdade das rendas é que a desigualdade do capital é sempre mais forte que a do trabalho. A distribuição da propriedade do capital e das rendas que dele provêm é sistematicamente mais concentrada do que a distribuição das rendas do trabalho.

Dois pontos merecem ser ressaltados de imediato. Primeiro, essa regularidade é encontrada em todos os países e em todas as épocas com dados disponíveis, sem exceção e sempre em grandes proporções. Apenas para destacar uma primeira ordem de grandeza, a participação dos $10 \%$ dos indivíduos que recebem as rendas do trabalho mais elevadas costuma ser de $25-30 \%$ do total das rendas do trabalho, enquanto a participação dos $10 \%$ dos indivíduos que detêm o patrimônio mais alto é sempre superior a $50 \%$ do total da riqueza, chegando às vezes a $90 \%$ em algumas sociedades. Talvez ainda mais marcante, os 50\% mais mal pagos recebem uma parte considerável do total das rendas do trabalho (geralmente entre um quarto e um terço, mais ou menos tanto quanto os $10 \%$ mais bem pagos), enquanto os $50 \%$ mais pobres em patrimônio não possuem nada - ou quase nada (sempre menos de $10 \%$ do patrimônio total e em geral menos de $5 \%$, ou dez vezes menos do que os $10 \%$ mais ricos). A desigualdade em relação ao trabalho é com frequência mais suave, moderada e razoável (ao menos até onde a desigualdade puder ser considerada 
razoável - veremos que essa questão não deve ser exagerada). Já a desigualdade do capital é sempre extrema. (PIKETTY, 2013, p. 11).

Importante a transcrição do referido trecho, pois, nele, PIKETTY (2013) demonstra, com maestria, como o capital tende a ser acumulado de forma acentuada. Ademais, principalmente em virtude do instituto da herança, o autor destaca que a riqueza é uma decorrência da própria riqueza, afastando o critério da meritocracia (PIKETTY, 2013, p. 368).

Muito embora tais constatações tenham sido realizadas com base em dados relativos a países europeus e aos Estados Unidos e ao Japão, dados recentes da realidade brasileira indicam que tal fato ocorre também no Brasil. MILÁ (2015), por exemplo, em estudo sobre a concentração de renda no Brasil, com base em dados dos anos 1933 a 2013, apresenta que, pelo menos desde a década de 1970, o $1 \%$ mais rico do país concentra cerca de $25 \%$ da riqueza nacional. Em estudo ainda mais atual, a Receita Federal do Brasil (2016, p. 09) confirmou, partindo de seu banco de dados, que a concentração de renda no país é intensa:

Considerando a razão ante o rendimento tributário médio, tem-se que o último milésimo da população declarante ganha $3.101 \%$ mais que a renda média nacional, enquanto o decil mais alto ganha 384\% Tabela 10. Quando se considera o rendimento total bruto, essa diferença é ainda maior, com o milésimo mais alto auferindo 6.090\% mais que a renda média nacional. (RECEITA FEDERAL, 2016, p. 09).

Desta forma, percebe-se que as constatações apresentadas por PIKETTY (2013) também se aplicam ao Brasil, de modo que devem-se buscar meios para que tal desigualdade seja reduzida. Segundo o autor, uma forma eficiente para reduzir o problema, seria a utilização da progressividade fiscal.

Como explica PIKETTY (2013, p. 480), a progressividade fiscal não é de todo nova, tendo surgido no séc. XX e apresentado resultados extremamente satisfatórios:

Veremos que a inovação mais importante do século XX em matéria fiscal foi a criação da e o desenvolvimento do imposto progressivo sobre a renda. Essa instituição desempenhou um papel central na redução da desigualdade ao longo do século passado, mas hoje está gravemente ameaçada pelas forças da concorrência fiscal entre os países. E também sem dúvida corre risco porque foi implementada em regime de urgência, deixando pouco espaço para uma reflexão sobre seus fundamentos. (PIKETTY, 2013, p. 480).

O período conturbado a que se refere o autor, em que se implementou com força a 
progressividade fiscal sem maiores reflexões, foi o período relativo às Grandes Guerras. Salvo algumas exceções, a maioria dos somente países apenas adotou a progressividade físcal de forma efetiva, em virtude do caos econômico vivenciado pela Europa no período, de modo a aumentar significativamente a arrecadação para manutenção dos custos gerados pelo conflito mundial (PIKETTY, 2013, p. 485/486).

Entretanto, ultrapassado o período conturbado, a grande maioria dos países abandonou a progressividade fiscal e, nos casos em que não abandonou, reduziu drasticamente, a ponto de não surtir efeitos positivos na questão da redistribuição do capital.

Desta forma, PIKETTY (2013, p. 492) defende o resgate do instituto, por se tratar de uma tributação justa e eficiente, já que permite que aqueles que possuam uma capacidade contributiva maior, efetivamente contribuam mais. Ademais, trata-se de uma forma de atuação do Estado pouco invasiva, que permite o funcionamento do capitalismo sem que sejam necessárias grandes modificações. Em suas palavras:

O imposto progressivo constitui sempre um método mais ou menos liberal para se reduzir as desigualdades, pois respeita a livre concorrência e a propriedade privada enquanto modifica os incentivos privados, às vezes radicalmente, mas sempre de modo previsível e contínuo, segundo regras fixadas com antecedência e debatidas de maneira democrática, no contexto de um Estado de Direito. O imposto progressivo exprime de certa forma um compromisso ideal entre justiça social e liberdade individual. Então, não é por acaso que os países anglo-saxões, que em certa medida se mostraram mais apegados à ideia das liberdades individuais ao longo da história, também tenham caminhado com mais firmeza na direção de uma progressividade fiscal ao longo do século XX. (PIKETTY, 2013, p. 492).

Analisando a proposta de utilização da progressividade como meio de efetivar a distribuição de renda, RIBEIRO (2015) concorda com o posicionamento de PIKETTY (2013), de que se trata de uma medida absolutamente compatível com o capitalismo e que não afetam as suas premissas:

\footnotetext{
Apesar da conclusão de que a concentração de renda e de capital é inerente ao modo de produção capitalista, e de que a partir dos anos de 1980 a desigualdade social tem aumentado a níveis comparáveis ao final do século XIX, Piketty não propõe a superação do capitalismo. Ao contrário, defende a adoção de medidas baseadas no liberalismo a partir do compromisso ideal entre justiça social e liberdade individual, necessário, necessário para a salvação da liberdade em um mundo globalizado, já que, na sua concepção a democracia estaria condenada pelo aumento vertiginoso da desigualdade. (RIBEIRO, 2015, p. 03).
}

Apresentado o quadro fático observado por PIKETY (2013), bem como sua 
semelhança com a realidade nacional, cabe analisar sua proposta de solução do quadro pela via do Direito Tributário e se, no caso do Brasil, o Direito nos autoriza a adotar suas proposições, tendo como base o sistema tributário nacional delineado pela Constituição e a jurisprudência firmada pelo Supremo Tribunal Federal.

\section{A PROGRESSIVIDADE NA CONSTITUIÇÃO DA REPÚBLICA E SUA SUBUTILIZAÇÃO}

A Constituição da República, norma máxima no Estado Democrático de Direito, delineia a estrutura do Estado, traçando suas bases, fundamentos e objetivos. Atualmente, não restam dúvidas quanto ao seu poder normativo, uma vez que, conforme nos ensina MELLO (2010, p. 11), ela "não é mero ideário. Não é apenas expressão de anseios, de aspiração, de propósitos. É a transformação de um ideário, é conversão de anseios e aspirações em regras impositivas. Em comando. Em preceitos obrigatórios para todos: órgão do Poder e cidadãos".

Por tais razões, em estudo sobre a formulação de políticas públicas, HOWLETT, RAMESH e PERL (2013, p. 158/159), bem explicam que, de fato, os agentes de Estado não gozam de liberdade absoluta na formulação destas, devendo observância ao arcabouço jurídico vigente:

\footnotetext{
“(...) o grau de liberdade de que gozam os tomadores de decisão de fato está circunscrito por uma grande quantidade de regras e estruturas restritivas que governam os cargos políticos bem como pelo conjunto de ideias e dos paradigmas e pelas circunstâncias sociais, econômicas e políticas no seio das quais eles operam. Conforme vimos anteriormente, as regras e estruturas básicas que afetam as configurações de poder e de recursos políticos, tanto entre os atores estatais como não estatais, variam desde a constituição do país até os mandatos específicos conferidos aos tomadores de decisão individuais. Os tomadores de decisões específicos, como os juízes e os servidores públicos, têm de agir no âmbito dos conjuntos específicos de leis e regulamentações, que governam seu comportamento e campos de competência (Markoff, 1975; Page 1985'; Atkinson e Coleman, 1989 ${ }^{\mathrm{a}}$ ) (...)". - (HOWLETT, RAMESH, PERL, 2013, p. 158/159).
}

No caso do Brasil, especificamente quanto ao tema em análise - utilização da progressividade fiscal como política pública de redução de desigualdade - é importante ressaltar que a Constituição da República tem como objetivos fundamentais, construir uma sociedade livre, justa e solidária (art. $3^{\circ}$, I) e erradicar a pobreza e a marginalização e 
reduzir as desigualdades sociais e regionais (art. $3^{\circ}$, III). Em consonância com tais objetivos fundamentais, o constituinte sistematizou o sistema tributário nacional de modo a atingir tais objetivos, dispondo que, sempre que possível, os impostos terão caráter pessoal e serão graduados segundo a capacidade econômica do contribuinte (art. $145, \S 1^{\circ}$ ). Em análise da ordem econômica na Constituição de 1988, GRAU (2012, p. 215) bem sintetiza:

\begin{abstract}
Objetivo fundamental da República Federal do Brasil é ainda o de erradicar a pobreza e a marginalização e reduzir as desigualdades sociais e regionais (art. $3^{\circ}$, III). Aí, também, um princípio constitucional impositivo (Canotilho) ou diretriz (Dworkin) - norma -objetivo - dotado de caráter constitucional conformador. Além disso, a redução das desigualdades regionais e sociais é tomada como um dos princípios da ordem econômica - princípio constitucional impositivo.

Erradicação da pobreza e da marginalização, bem assim redução das desigualdades sociais e regionais, são objetivos afins e complementares daquele atinente à promoção (=garantir) do desenvolvimento econômico. Considere-se também o princípio positivado no inciso IV deste art. $3^{\circ}$ : promover o bem de todos; e a dignidade da pessoa humana como fundamento da República, mais o assegurar a todos existência digna como fim da ordem econômica. (GRAU, 2012, p. 215)
\end{abstract}

Segundo TORRES (2011, p. 515), estas disposições, por constituírem verdadeiros objetivos a serem alcançados, "são regra vinculantes de todo o ordenamento para um fim geral ou específicos, que obrigam ao máximo de observância e efetividade e vedam qualquer conduta em sentido contrário ao seu conteúdo teleológico". Entretanto, não obstante seja nítida a opção do constituinte pela progressividade, como corolário lógico da capacidade contributiva, o sistema tributário infraconstitucional caminha em sentido contrário. É o que explica COÊLHO (2012, p. 300):

\begin{abstract}
A progressividade é instrumento técnico e também princípio, na dicção constitucional, que conduz à elevação das alíquotas à medida que cresce o montante tributável, indicativo da capacidade econômica do contribuinte. No Brasil (art. 155, $\S 2^{\circ}, \mathrm{I}$ ), a sua adoção é obrigatória. O legislador ordinário está obrigado a conferirlhe eficácia, embora a sociedade, dormente, aceite que este atue à la diable nesta questão, por insuficiente consciência de cidadania (COÊLHO, 2012, p. 300)
\end{abstract}

Por outro lado, importante destacar que tais princípios não são incompatíveis com a economia de mercado, adotada pela Constituição, que também estabelece como princípios a liberdade econômica e a livre iniciativa. Pelo contrário, são modelos absolutamente compatíveis, conforme leciona RIBEIRO (2015): 
produto da sua ordem jurídica, não só em relação às leis que regem a propriedade e as relações para a sua aquisição e transferência, mas também em relação as normas ficais, previdenciárias e políticas. Deste modo, o combate à desigualdade poder ser compatível com a liberdade individual e a livre iniciativa desde que estas sejam harmonizadas com a justiça social por meio de uma tributação capaz de promover a redistribuição de riquezas. (RIBEIRO, 2015, p. 07).

No caso do Brasil, apesar das diretrizes constitucionalmente previstas, a inobservância da capacidade contributiva e da progressividade fiscal ocorrem de duas maneiras pelo legislador. A primeira, é por dar maior importância à tributação sobre o consumo, ao invés da renda. Isso porque, na tributação sobre o consumo, todos aqueles que são consumidores pagam a mesma quantia de impostos sobre os produtos, não havendo distinção conforme a capacidade econômica de cada um, fazendo com que as camadas mais pobres gastem, proporcionalmente, mais com tal tributação.

A segunda forma, se dá na própria tributação sobre a renda, que, apesar de ter melhores condições de respeitar a capacidade de cada contribuinte, não é feita de forma adequada no Direito brasileiro, na medida em que o legislador faz pouco uso da progressividade. Isso porque, o legislador instituiu apenas quatro faixas de alíquotas do Imposto de Renda, até a máxima, de apenas $27,5 \%$. Em respeito à progressividade e a capacidade do contribuinte, o ideal seria que o legislador adotasse um número maior de faixas e, ainda, que não se limitasse ao montante de $27,5 \%$, que é insuficiente como política pública de distribuição de renda. Sobre cada um dos tipos de tributos, explica PIKETTY (2013, p. 481):

Classicamente, faz-se uma distinção entre os impostos sobre a renda, os impostos sobre o capital e os impostos sobre o consumo. Podemos encontrar arrecadações relevantes nesses três conjuntos em quase todas as época, em proporções diversas. Contudo, essas categorias não são isentas de ambiguidades, e as fronteiras nem sempre são perfeitamente claras. Por exemplo, o imposto sobre a renda se aplica, em princípio, tanto às rendas do capital quanto às do trabalho: trata-se, assim, de um imposto em parte sobre o capital. Por sua vez, em geral se incluem nos impostos sobre o capital as arrecadações sobre o fluxo de renda do capital (por exemplo, os lucros das empresas), e elas se baseiam no valor do estoque do capital (por exemplo, a contribuição predial, o imposto sobre as heranças ou o imposto sobre a fortuna). Os impostos sobre o consumo compreendem, hoje em dia, os combustíveis, o tabaco, ou um bem ou serviço em particular. Esses impostos existem desde sempre e são muitas vezes os mais detestados e os mais oneroso para as classes populares, como a gabela (imposto sobre o sal) no Antigo Regime. Com frequência dizemos que eles são "indiretos", no sentido de que não dependem diretamente da renda ou do capital do contribuinte individual: são pagos de forma indireta, por intermédio do preço de venda, quando fazemos compras. Em teoria, podemos de fato imaginar um 
imposto direto sobre o consumo, que dependerá do montante consumido por cada um, mais isso nunca ocorreu. (PIKETTY, 2013, p. 481).

O que se tem, portanto, é que é preciso caminhar para uma reforma tributária que efetivamente privilegie o princípio da capacidade contributiva, a fim de possibilitar que o excesso de capital existente nas classes economicamente superiores seja redistribuído para as classes mais pobres por intermédio do Estado.

\section{O DEVER FUNDAMENTAL DE PAGAR IMPOSTOS}

O Estado contemporâneo trouxe para si um enorme número de atribuições, sobretudo no campo social, devendo prover educação, saúde, segurança, transporte público, previdência social, dentre outras funções. Ocorre que, para que dê efetividade às suas competências, é preciso arrecadação, que se dá, em sua maior parte, por meio da tributação. Bem lembra ATALIBA (2011, p. 29) que "Os políticos (homens que dirigem o estado), precisando atender às necessidades financeiras do poder público, usam do direito como instrumento do desígnio de abastecer o estado de dinheiro".

Neste sentido, para que o Estado exerça suas funções, é essencial que seja abastecido por meio da tributação, sem o qual torna-se inviabilizado todo o arcabouço constitucional. Por isso, NABAIS (1998, p. 62) defende que é na Constituição que deve-se basear o dever fundamental de pagar impostos, posto que "o fundamento de cada dever fundamental não se baseia numa cláusula de generosidade social, devendo, pois ter na constituição um suporte expresso ou implícito. O que significa, de um lado, que só a constituição é fundamento dos deveres fundamentais".

Partindo da premissa estabelecida por NABAIS (1998), de que o dever fundamental deve ser buscado na Constituição, não restam dúvidas quanto à sua existência no Direito brasileiro, seja pela previsão expressa da capacidade contributiva no texto constitucional, conforme demonstrado anteriormente, seja pelas normas que atribuem ao Estado uma séria de competências que demandam recursos públicos, que têm como fonte a tributação.

Entretanto, o sistema tributário não se resume ao abastecimento dos cofres públicos. Em verdade, segundo BARROS (2016, p. 238), é possível o “(...) emprego de fórmulas jurídico-tributárias para a obtenção de metas que prevalecem sobre os fins simplesmente arrecadatórios de recursos monetários (...)” ou, nas palavras de COÊLHO (2012, p. 234) "a 
utilização dos tributos para fins outros que não os da simples arrecadação de meios para o Estado. Nesta hipótese, o tributo é instrumento de políticas econômicas, sociais, culturais, etc.".

Ou seja, a tributação não é só meio para arrecadação do Estado, mas também, instrumento de política pública, por meio de suas funções extrafiscais. NABAIS (1998, p. 630) sintetiza tal função:

\begin{abstract}
A extrafiscalidade traduz-se no conjunto de normas que, embora formalmente integrem o direito fiscal, tem por finalidade principal ou dominante a consecução de determinados resultados económicos ou sociais através da utilização do instrumento fiscal e não a obtenção de receitas para fazer face às despesas públicas. Trata-se assim de normas (fiscais) que, preverem uma tributação, isto é, uma ablação ou amputação pecuniária (impostos), ou uma não tributação ou uma tributação menos à requerida pelo critério da capacidade contributiva, isto é, uma renúncia total ou parcial a essa ablação ou amputação (benefícios fiscais), estão dominadas pelo intuito de actuar diretamente sobre os comportamentos económicos e sociais dos seus destinatários, desincentivando-os, neutralizando-os nos seus efeitos económicos e sociais ou fomentando-os, ou seja, de normas que contêm medidas de política económica e social. (NABAIS, 1998, p. 630).
\end{abstract}

Portanto, não restam dúvidas quanto a possibilidade de utilização do Direito Tributário como política pública. E, como afirmamos anteriormente, as políticas públicas devem ser estabelecidas tendo como base as diretrizes constitucionais. Assim, considerando que no caso brasileiro a Constituição estabelece expressamente como um dos objetivos do Estado a redução das desigualdades sociais e regionais, bem como a erradicação da pobreza e, ainda, a capacidade contributiva como fundamento da própria tributação, tem-se como absolutamente viável a utilização do Direito Tributário como instrumento efetivo de distribuição de renda, como proposto por PIKETTY (2013).

Neste sentido, RIBEIRO (2015, p. 08) demonstra como a progressividade pode servir como fonte de renda para o Estado e, mais ainda, como política adequada e eficiente para a redistribuição de renda:

Se a progressividade da tributação da renda e das heranças, como elemento essencial à redistribuição de rendas, é fundamental ao financiamento das prestações positivas exigidas pelo Estado Social, a distribuição de rendas por meio da tributação dos grandes capitais é condição central para a regulação do capitalismo. É que, ainda que as receitas advindas da tributação dos grandes capitais não fossem tão relevantes em relação ao orçamento público, a instituição do imposto seria importante instrumento, no dizer de Piketty para "evitar a espiral desigualadora sem fim e uma divergência ilimitada das desigualdades patrimoniais, além de possibilitar um controle eficaz das crises financeiras e bancárias" . (RIBEIRO, 2015, p. 08) 
Este dever fundamental de pagar impostos, sistematizado por NABAIS (1998), restou reconhecido pelo Supremo Tribunal Federal, que no julgamento conjunto das ADI's 2.390, 2.386, 2.397 e 2.859, julgadas em fevereiro de 2016 pelo do tribunal, sob a relatoria do Ministro Dias Toffoli, consignou que:

\begin{abstract}
A ordem constitucional instaurada em 1988 estabeleceu, dentre os objetivos da República Federativa do Brasil, a construção de uma sociedade livre, justa e solidária, a erradicação da pobreza e a marginalização e a redução das desigualdades sociais e regionais. Para tanto, a Carta foi generosa na previsão de direitos individuais, sociais, econômicos e culturais para o cidadão. Ocorre que, correlatos a esses direitos, existem também deveres, cujo atendimento é, também, condição sine qua non para a realização do projeto de sociedade esculpido na Carta Federal. Dentre esses deveres, consta o dever fundamental de pagar tributos, visto que são eles que, majoritariamente, financiam as ações estatais voltadas à concretização dos direitos do cidadão. (SUPREMO TRIBUNAL FEDERAL, ADI 2.859, 2016)
\end{abstract}

Ainda mais incisivo foi o voto do Ministro Luís Roberto Barroso, entrelaçando a solidariedade com o princípio da capacidade contributiva e o dever fundamental de pagar tributos:

\begin{abstract}
Nesse ponto, algumas aproximações são inevitáveis. A primeira delas é com a definição de tributo como um dever fundamental. É comum que as pessoas após alguns séculos se esqueçam que as principais formulações sobre o contrato social o conceberam com um acordo entre pessoas e não entre essas e o Estado, o que é um desvio de percepção bastante comum. Se a criação do Estado é um projeto coletivo, deve-se reconhecer que a solidariedade se projeta com muita força no direito fiscal, que se traduz na disciplina da repartição igualitária dos custos dos direitos prestados e/ou garantidos pelo Estado. Nesse contexto, o pagamento de tributos constitui-se um dever fundamental estabelecido constitucionalmente. Dever esse juridicamente fundamentado quer na feição fiscal assumida pelo Estado contemporâneo, quer no elenco de direitos fundamentais constitucionalmente previstos e que se pressupõem o necessário financiamento". (SUPREMO TRIBUNAL FEDERAL, ADI 2.859, 2016)
\end{abstract}

Percebe-se, portanto, que a teoria desenvolvida por NABAIS (1998) também guarda respaldo em nossa Constituição, que, conforme reconhecido pelo Supremo Tribunal Federal, prevê o dever fundamental de pagar impostos.

A relação de tal teoria, com a proposta de PIKETTY (2013), de utilização do sistema progressivo como política pública de distribuição de renda está precisamente no fato de que ambas se sustentam na noção de capacidade contributiva - vale dizer, quanto mais riqueza determinado individuo exteriorizar, maior deverá ser a tributação sobre sua renda, uma vez que possui o dever fundamental de pagar tributos e, pelos princípios e objetivos que orientam 
nosso ordenamento jurídico, deve contribuir para a redução de desigualdade social e da concentração de renda. A importância da capacidade contributiva como critério maior é enfatizado por NABAIS (1998, p. 441):

\begin{abstract}
Depois, todos devem estar adstritos ao pagamento de impostos com base no mesmo critério. E eis aqui o segundo aspecto da igualdade fiscal - a uniformidade dos impostos -, segundo a qual a repartição destes deve obedecer ao mesmo critério, um critério idêntico para todos os destinatários do dever de pagar impostos. E quanto a qual deva ser esse critério, não há actualmente divergências que o mesmo deve ser o da capacidade contributiva (stuerliche Leistungsfähigkeit, taxable capacity) ou capacidade econômica (wirtschaftliche Leistungsfähigkeit) ou capacidade de pagar (abilty to pay), expressões que utilizamos aqui como sinónimas, muito embora seja a primeira a mais tradicional (NABAIS, 1998, p. 441).
\end{abstract}

Neste contexto, verifica-se que a utilização da tributação sobre a renda obedece melhor ao critério da capacidade contributiva, sendo a norma mais adequada e justa de tributação e que merece ser melhor acolhida e desenvolvida pelo legislador nacional.

\title{
5. CONSIDERAÇÕES FINAIS
}

Apresentadas as constatações de PIEKTTY (2013) sobre a estrutura da concentração de renda no mundo, o que se percebe é que a desigualdade social tende a se acentuar cada vez mais, uma vez que que quanto maior a desigualdade, mais ele tende a se aprofundar, na medida em que o acúmulo de capital favorecer o seu ganho.

Estas constatações, conforme estudos apresentados por MILÁ (2015) e pela Receita Federal do Brasil (2016), também estão presentes na realidade brasileira e, por isso merecem atenção.

Entretanto, apesar do trabalho de Piketty ser revelador de grandes problemas mundiais, é de certa forma confortante, pois apresenta soluções possíveis e alcançáveis. E, como visto, as soluções propostas pelo autor são viáveis e, mais ainda, são absolutamente compatíveis com o Direito brasileiro, que, inclusive, as orientam.

Isso porque, conforme desenvolvido nos capítulos anteriores, a proposta de PIKETTY (2013) pela utilização da progressividade fiscal foi também uma opção do constituinte, que a previu expressamente, aliada à noção de capacidade contributiva. Aliás, tal concepção resta fortalecida com a teoria de NABAIS (1998), que sistematiza o dever 
fundamental de pagar impostos, para que o Estado atinja sua finalidade. E, como vimos, tal teoria também foi recepcionada pelo Direito brasileiro, restando inclusive reconhecida pelo Supremo Tribunal Federal.

É importante ressaltar que, conforme devidamente explicado por PIKETTY (2013), a progressividade fiscal não só é eficiente na distribuição de renda, como também é absolutamente compatível com o modelo capitalista, pois não descontrói suas bases, assentadas na meritocracia e no lucro, que permanecem vigentes e íntegras com tal modelo tributário.

Portanto, estabelecidas todas estas premissas, percebe-se que os agentes de Estado brasileiros, sobretudos os legisladores e membros do Poder Executivo, que estão à frente na formulação de políticas públicas, subutilizam um instituto extremamente importante e que merece ser melhor aprofundado, porque justo e juridicamente possível.

Feitas tais considerações, conclui-se pela inviabilidade do modelo tributário vigente, demasiadamente custoso para o país, uma vez que atribuiu às classes menos abastadas altas tributações, especialmente através do consumo, enquanto que, por outro lado, o imposto sobre a renda possui pouquíssimas faixas de alíquotas e um limite máxima baixo, que não favorece a redistribuição de renda, que seria uma finalidade extrafiscal destes tributos.

Por outro lado, cabe reconhecer que a elaboração de relatórios como o da Distribuição Pessoal da Renda e da Riqueza da População Brasileira elaborado pela Receita Federal em 2016 é, de certa forma, um grande passo para o desenvolvimento de novas políticas públicas, uma vez que permite a sistematização de dados concretos sobre a concentração de renda. A importância destes dados é inequívoca, e comprovável pelo fato, por exemplo, de que grande parte do estudo desenvolvido por PIKETTY (2013) se deu com base na análise de dados tributários, sobretudo acerca da renda, o que demonstra a importância e relevância de tais estudos - aliás, a obra de PIKETTY (2013) é justamente um dos fatores que motivaram a sistematização dos dados, conforme consignado no próprio relatório (Receita Federal, 2016, p. 06).

\section{REFERENCIAS}

ATALIBA, Geraldo. Hipótese de incidência tributária. $6^{\mathrm{a}}$ edição, $12^{\mathrm{a}}$ tiragem. São Paulo: Malheiros, 2011. 
BANDEIRA DE MELLO, Celso Antônio. Eficácia das normas constitucionais e Direitos sociais. $1^{\text {a }}$ ed., $3^{\mathrm{a}}$ tir. São Paulo: Malheiros, 2010.

BRASIL. Constituição da República Federativa do Brasil de 1988.

CARVAlHO, Paulo de Barros. Curso de Direito Tributário. $27^{\text {a }}$ edição. São Paulo: Saraiva, 2016.

COÊLHO, Sacha Calmon Navarro. Curso de Direito Tributário Brasileiro. $12^{\mathrm{a}}$ edição. Rio de Janeiro: Forense, 2012.

GRAU, Eros Roberto. A ordem econômica na Constituição de 1988. $15^{\text {a }}$ edição. São Paulo: Malheiros, 2012.

HOWLETT, Michael.; RAMESH, M; PERL, A. Política Pública: seus ciclos e subsistemas: uma abordagem integradora. Tradução de Francisco G. Heidemann. Rio de Janeiro: Elsevier, 2013.

MELlO, Celso Antônio Bandeira de. Eficácia das normas constitucionais e direitos sociais. $1^{\mathrm{a}}$ edição, $3^{\mathrm{a}}$ tiragem. São Paulo: Malheiro, 2011.

MINISTÉRIO DA FAZENDA. Relatório da distribuição de pessoal da renda e da riqueza da população brasileira. Secrataria de Política Econômica - SPE. Maio de 2016. Disponível em: $\quad$ http://www.fazenda.gov.br/centrais-de-conteudos/publicacoes/transparenciafiscal/distribuicao-renda-e-riqueza/relatorio-distribuicao-da-renda-2016-05-09.pdf

MILÁ, Marc Morgan. Income concentration in a contexto of late development: an investigation of top income in Brazil using tax records, 1933-2013. Public Policy and Development máster dissertation. Paris School of Economics, setembro de 2015. Disponível em:

http://piketty.pse.ens.fr/files/MorganMila2015.pdf

NABAIS, José Casalta Nabais. O dever fundamental de pagar impostos. Coimbra: Livraria Almedina, 1998.

PIKETTY, Thomas. O Capital no século XXI. Trad.: Monica Baumgarten de Bolle. Rio de Janeiro: Intrínseca, 2013.

RIBEIRO, Ricardo Lodi. Piketty e a reforma tributária no Brasil. Revista de Finanças Públicas, Tributação e Desenvolvimento, v. 3, n. 3, 2015. Disponível em:

https://www.google.com.br/url?sa=t\&rct=j\&q=\&esrc=s\&source=web\&cd=2\&ved=0ahUKEw ik_p6QjOTTAhWIIJAKHWWCCskQFggrMAE\&url=http\%3A\%2F\%2Fwww.epublicacoes.uerj.br\%2Findex.php\%2Frfptd\%2Farticle\%2Fdownload\%2F15587\%2F11798\&u sg=AFQjCNG7M5X82oZbcGZ4y92YKOxsZfQ6Yg 
SUPREMO TRIBUNAL FEDERAL. Ação Direta de Inconstitucionalidade 2.859. Relator Ministro Dias Toffoli, Tribunal Pleno, DJ 20/10/2016. Disponível em: http://www.stf.jus.br/portal/jurisprudencia/listarJurisprudencia.asp?s1=\%28ADI\%24\%2ESCL A $\% 2 \mathrm{E}+\mathrm{E}+2390 \% 2 \mathrm{ENUME} \% 2 \mathrm{E} \% 29+\mathrm{OU}+\% 28 \mathrm{ADI} \% 2 \mathrm{EACMS} \% 2 \mathrm{E}+\mathrm{ADJ} 2+2390 \% 2 \mathrm{EACM}$ $\underline{\mathrm{S} \% 2 \mathrm{E} \% 29 \& \text { base }=\text { base Acordaos\&url=http://tinyurl.com/bf2wcle }}$

TORRES, Heleno Taveira. Direito Constitucional Tributário e a segurança jurídica: metódica da segurança jurídica do sistema constitucional tributário. São Paulo: Revista dos Tribunais, 2011. 